\title{
Implementasi pembelajaran nonformal pada Sekolah Dasar Quran Hanifah di Kota Semarang
}

\author{
Imam Shofwan ${ }^{1 *}$, Ghanis Putra ${ }^{2}$, Tristanti Tristanti ${ }^{3}$ \\ ${ }^{1}$ Pendidikan Luar Sekolah, Universitas Negeri Semarang. \\ Kampus Sekaran, Gunungpati, Semarang 50229, Indonesia \\ ${ }^{2}$ Teknologi Pendidikan, Universitas Negeri Semarang. \\ Kampus Sekaran, Gunungpati, Semarang 50229, Indonesia \\ 3 Pendidikan Luar Sekolah, Universitas Negeri Yogyakarta. \\ Jalan Colombo No. 1, Karangmalang, Yogyakarta 55281, Indonesia \\ * Corresponding Author. Email: ishofwan@mail.unnes.ac.id \\ Received: 3 February 2019; Revised: 11 February 2019; Accepted: 13 March 2019
}

\begin{abstract}
Abstrak
Tujuan penelitian untuk mengetahui implementasi pembelajaran nonformal yang berkaitan dengan perencanaan pembelajaran, pelaksanaan pembelajaran dan evaluasi pembelajaran yang berbeda dengan sekolah dasar formal pada umumnya. Penelitian ini menggunakan pendekatan penelitian kualitatif dengan teknik pengumpulan data menggunakan metode observasi partisipan, wawancara bebas terpimpin dan dokumentasi untuk mendapatkan data dan informasi akurat dengan pengetahuan yang mendalam tentang implementasi pembelajaran nonformal Sekolah Dasar Quran Hanifah Kota Semarang yang menggunakan pembelajaran yang berbeda dengan sekolah pada umumnya degan tujuan pembelajarannya adalah berakhlaqul karimah dan mampu menghafal Alquran. Hasil penelitian (1) perencanaan pembelajaran nonformal yang diselenggarakan sesuai dengan kalender akademik yang diberikan kepada orangtua; (2) proses pelaksanaan pembelajaran nonformal diawali dan diakhiri dengan doa serta dibuat peraturan (adab) dalam belajar yang mengedepankan tahfidz atau hafalan, (3) evalusi pembelajaran nonformal dilakukan di awal dengan tes kemampuan membaca, evaluasi proses dengan tes hafalan dan evaluasi akhir dengan tes ujian hafalan mingguan dan bulanan; dan (4) faktor pendukung adanya kegiatan parenting 2 (dua) mingguan serta penghambat tempat yang sempit dan kualifikasi pendidik belum lulus sarjana.
\end{abstract}

Kata Kunci: implementasi pembelajaran, pembelajaran nonformal, sekolah tahfidz

\section{Implementation of nonformal learning in Hanifah Quran Primary Schools in Semarang City}

\begin{abstract}
The purpose of the study was to determine the implementation of non-formal learning related to learning planning, the implementation of learning, and evaluation of learning that was different from formal elementary schools in general. This study uses a qualitative research approach with data collection techniques using participant observation, guided free interviews and documentation to obtain accurate data and information with in-depth knowledge about the implementation of nonformal learning in the Hanifah Quran Primary School in Semarang that uses learning that is different from the school in general. Research results (1) non-formal learning planning held in accordance with the academic calendar given to parents; (2) the process of implementing non-formal learning begins and ends with prayer and rules (adab) in learning that promote tahfidz or memorization, (3) nonformal learning evaluation is carried out at the beginning with reading ability tests, process evaluation with memorization tests and final evaluation with tests weekly and monthly memorization tests; and (4) supporting factors for 2 weekly parenting activities and narrow space barriers and the qualifications of educators have not yet graduated.
\end{abstract}

Keywords: implementation of learning, nonformal learning, tahfidz schools

How to Cite: Shofwan, I., Widhanarto, G., \& Tristanti, T. (2019). Implementasi pembelajaran nonformal pada Sekolah Dasar Quran Hanifah di Kota Semarang. JPPM (Jurnal Pendidikan dan Pemberdayaan Masyarakat), 6(1), 1-10. doi:https://doi.org/10.21831/jppm.v6i1.23434

d.

https://doi.org/10.21831/jppm.v6i1.23434 
JPPM (Jurnal Pendidikan dan Pemberdayaan Masyarakat), 6 (1), 2019 - 2

Imam Shofwan, Ghanis Putra, Tristanti Tristanti

\section{PENDAHULUAN}

Pendidikan merupakan unsur yang paling strategis bagi pembangunan suatu bangsa. Peran adanya pendidikan akan berpengaruh kepada sumberdaya manusia secara kualitas dan kuantitas, sehingga dapat meningkatkan kesejahteraan dan kemakmuran masyarakat dalam suatu negara dan pada akhirnya dapat mengangkat derajat dan martabat bangsa itu sendiri (Shofwan \& Kuntoro, 2014, p. 51). Pendidikan adalah proses pembentukan tingkah laku dan kemampuan seseorang yang dapat berguna bagi bangsa dan negara. (Nengsih, Sari, \& Helmi, 2018, p. 52). Suatu bangsa atau negara dapat dikatakan semakin maju dan juga berkembang diantaranya, apabila dalam pembangunan di bidang pendidikan diberikan perhatian secara maksimal dengan upaya penyediaan fasilitas, sarana dan prasarana untuk memenuhi pendidikan masyarakatnya. Pembangunan akan berjalan dengan baik apabila sumber daya manusia sebagai subjek pembangunan dikembangkan melalui kegiatan pendidikan yang relevan dengan pembangunan (Hidayat, 2016, p. 14).

Pendidikan adalah suatu keharusan untuk mencerdaskan kehidupan suatu bangsa dan negara. Untuk itu yang dipersiapkan adalah lembaga-lembaga pendidikan yang dapat melayani kebutuhan pendidikan warga masyarakatnya mulai dari pendidikan pra sekolah sampai pendidikan sekolah tinggi. Seyogyanya secara baik dilaksanakan baik oleh jalur pendidikan formal, nonformal dan informal sesuai dengan UUSPN No. 20 tahun 2013 pasal 13 yang berbunyi jalur pendidikan terdiri atas pendidikan formal, nonformal, dan informal yang dapat saling melengkapi dan memperkaya. Pendidikan formal maupun nonformal merupakan lembaga vital yang berperan utama sebagai kunci untuk mempersiapkan kebutuhan masa depan bangsa berdasarkan aspek intelektual, dan memadukan aspek keterampilan dengan kepribadian. (Departemen Pendidikan Nasional Republik Indonesia, 2006).

Adapun tujuan pendidikan menurut (Delors, 1998) yang kemudian dikenal dengan empat pilar pendidikan versi UNESCO (1996) yang harus mendapatkan perhatian, yaitu: (1) learning to know, untuk mengetahui; (2) learning to do, belajar untuk dapat berbuat; (3) learning to be, belajar untuk menjadi dirinya; dan (4) learning to live together, belajar untuk hidup bersama dengan orang lain.

Berkaitan dengan pengertian pendidikan sesuai yang termaktub dalam UUSPN No. 20 Tahun 2003 adalah bahwa pendidikan adalah usaha sadar dan terencana untuk mewujudkan suasana belajar dan proses pembelajaran agar peserta didik secara aktif mengembangkan potensi dirinya untuk memiliki kekuatan spiritual keagamaan, pengendalian diri, kepribadian, kecerdasan, akhlak mulia, serta keterampilan yang diperlukan dirinya, masyarakat, bangsa dan negara (Presiden Republik Indonesia, 2003).

Begitu juga dengan tujuan pendidikan nasional yaitu pendidikan nasional berfungsi mengembangkan kemampuan dan membentuk watak serta peradaban bangsa yang bermartabat dalam rangka mencerdaskan kehidupan bangsa, bertujuan untuk berkembangnya potensi peserta didik agar menjadi manusia yang beriman dan bertakwa kepada Tuhan Yang Maha Esa, berakhlak mulia, sehat, berilmu, cakap, kreatif, mandiri, dan menjadi warga negara yang demokratis serta bertanggung jawab. Senada dengan pendapatnya (Ernawati \& Mulyono, 2017, p. 61) pendidikan adalah usaha dasar untuk mewujudkan dan mengembangkan potensi manusia. Fungsi pendidikan itu sendiri untuk mengembangkan kemampuan, membentuk watak, peradaban yang bermanfaat (Ningrum, 2016).

Sesuai dengan pengertian dan tujuan pendidikan nasional tersebut bahwa, pendidikan yang baik adalah pendidikan yang tidak menghilangkah roh religus di dalamnya. Adapun tujuan pendidikan formal yang selama ini lebih mementingkan akademis saja, senada dengan pendapat (Vibriyanthy \& Fauziah, 2014, p. 76) persekolahan selama ini lebih menekankan pengembangan kemampuan intelektual untuk mampu mengerjakan soal-soal ujian semata sehingga kurang memberikan perhatian pada pengembangan karakter siswa.

Hal ini dibuktikan kondisi di lapangan sekarang ini sekolah sudah berlomba-lomba 
JPPM (Jurnal Pendidikan dan Pemberdayaan Masyarakat), 6 (1), 2019 - 3

Imam Shofwan, Ghanis Putra, Tristanti Tristanti

untuk mempunyai karakteristik atau ciri khas tersendiri dalam melakukan pelaksanaan pendidikan yang output-nya adalah prestasi untuk melanjutkan sekolah yang lebih tinggi lagi.

Lebih lanjut berkaitan dengan tujuan pendidikan nonformal adalah untuk memenuhi kebutuhan pendidikan atau kebutuhan belajar warga masyarakat dimana kebutuhan pendidikan sangat beragam, dengan memberikan pengetahuan, keterampilan dan nilai-nilai yang dibutuhkan dalam rangka meningkatkan kualitas kepribadian, meningkatkan kesejahteraan hidup, membangun kehidupan sosial yang dinamis, dan terwujudnya kehidupan berpolitik yang partisipatoris. (Suryono \& Tohani, 2016). Inilah yang menjadi dasar bahwa pendidikan nonformal adalah pendidikan yang yang diselenggarakan bukan hanya sekedar untuk kepentingan melanjutkan sekolah yang lebih tinggi lagi, tapi pendidikan luar sekolah tujuannya adalah untuk menyiapkan hidup yang berkualias dalam hidupnya.

Berkaitan dengan prinsip pembelajaran Sekolah Dasar Quran Hanifah kota Semarang Hanifah adalah memadukan antara pendidikan nonformal untuk hidup yang berkualitas dan pendidikan berbasis Alquran untuk bekal di akhirat kelak. Berkaitan dengan pendidikan anaknya untuk memilih sekolah, Orangtua atau masyarakat sekarang memunyai banyak pilihan dalam memasukkan sekolah anak-anaknya yang disesuaikan dengan harapan atau tujuan mereka agar menjadi manusia yang sukses untuk masa depannya.

Apalagi sekarang banyak permasalahan berkaitan dengan dunia pendidikan, mulai dari permasalahan kriminal, tindak asusila atau peleceha seksual dan berkaitan dengan perilaku yang menyimpang. Kebanyakan sekolah formal mengalami kesulitan untuk melakukan kontrol pengawasan dan pengendalian kepada para pelajar dari jeratan negatif arus globalisasi informasi dan modernitas. Untuk itulah, sekarang ini yang banyak orangtua berfikir dua kali dalam memilih sekolah untuk anak kesayangannya.

Sekolah yang mempunyai karakteristik atau ciri khas tentunya mempunyai nilai lebih yang sekarang ini banyak diminati oleh orang tua. Karena mereka menginginkan anaknya selain melakukan sekolah juga menginginkan anaknya tidak hanya pintar dalam sekolah, akan tetapi juga mempunyai kemampuan dalam hal lainnya yang bisa menunjang agar lebih mandiri hidupnya yang akan datang. Hal ini senada dengan hakikat Pendidikan menurut pendapatnya (Lestari \& Suminar, 2016) yaitu hakikat pendidikan kecakapan hidup dalam pendidikan nonformal adalah upaya untuk meningkatkan keterampilan, pengetahuan, sikap, dan kemampuan yang memungkinkan peserta didik dapat mandiri dan sukses dalam hidupnya.

Pendidikan adalah suatu keharusan untuk mencerdaskan kehidupan suatu bangsa dan negara. Untuk itu yang dipersiapkan adalah lembaga-lembaga pendidikan yang dapat melayani kebutuhan pendidikan warga masyarakatnya mulai dari pendidikan pra sekolah sampai pendidikan sekolah tinggi. Sekolah Dasar Quran Hanifah kota Semarang adalah sekolah dasar yang berbeda dengan sekolah formal lainnya. Adanya keunikan tersendiri diantaranya pembelajaran yang berbeda dengan sekolah formal, pembelajaran yang mengedepankan pengetahuan alquran dari pada pengetahuan umum. Selain itu sekolah ini lebih memilih menggunakan jalur pendidikan nonformal dari pada jalur pendidikan formal.

Pemilihan menggunakan pembelajaran nonformal dilakukan karena dalam pembelajaran lebih mementingkan prosesnya daripada hasil pembelajarannya, lebih mementingkan afektif dan psikomorik daripada kognitif. Tidak seperti jalur pendidikan formal yang lebih mementingkan kognitif atau pengetahuan baru diikuti afektif dan psikomotiknya sehingga proses pembelajarannya berkesan hanya mentransfer pengetahuan saja.

Sekolah Dasar Quran Hanifah Kota Semarang inilah yang menjadikan alasan peneliti untuk mengungkap impementasi pembelajaran nonformal yang dilakukannya. Selain berbeda dengan sekolah dasar pada umumnya, sekolah ini bisa berjalan dengan baik dan tidak kalah dengan sekolah dasar yang ada di lingkunganya. Selain itu sekolah ini mempunyai keunggulan tersendiri, karena peserta didik mempunyai kemampuan dalam hafalan Alquran yang tidak ada pada sekolah 


\section{JPPM (Jurnal Pendidikan dan Pemberdayaan Masyarakat), 6 (1), 2019 - 4}

Imam Shofwan, Ghanis Putra, Tristanti Tristanti

dasar pada umumnya. Sehingga nantinya setelah lulus diharapkan sudah hafal Alquran atau menjadi Hafidz dan Hafidhoh dan juga menjadi insan Qurani dalam kehidupannya.

Berkaitan dengan kesuksesan dalam hidupnya, tidak hanya memikirkan dunia tetapi juga memikirkan akhirat. Maka dalam pelaksanaan sekolah perlu malakukan proses pembelajaran nonformal, yang tidak hanya mentransfer pengetahuan semata, akan tetapi perlu adanya pengembangan kemampuan atau potensi dan juga kepribadian atau karakter yang baik untuk memberikan pondasi kehidupan awal peserta didik.

Sekolah Dasar Quran Hanifah di kota Semarang merupakan sekolah yang memunyai karakteristik atau ciri khas yang membedakan dengan sekolah dasar lainnya. Pembelajaran yang lebih mengutamakan hafalan Alquran dan mementingkan akhlaqulkarimah serta entrepreneurship dalam proses pembelajaran. Inilah yang membedakan dalam proses pembelajaran yang diterapkan pada sekolah dasar formal, yang lebih mementingkan penguasaan pengetahuan mata pelajaran pada umumnya.

\section{METODE}

Penelitian ini menggunakan pendekatan kualitatif untuk mengetahui implementasi pembelajaran nonformal berkaitan dengan: (1) perencanaan pembelajaran; (2) pelaksanaan pembelajaran; dan (3) evaluasi pembelajaran nonformal; serta (4) faktor penghambat dan pendukung dalam pembelajaran pada Sekolah Dasar Quran Hanifah di Kota Semarang. Penelitian ini dilaksanakan pada bulan Maret 2018 sampai dengan September 2018. Subjek penelitian adalah pendiri, kepala sekolah, dan pendidik Sekolah Dasar Quran Hanifah. Pengumpulan data dilakukan melalui (1) observasi partisipasi dengan mengunjungi langsung tempat penelitian dan melihat proses pembelajaran yang dilaksanakan dari awal pembelajaran sampai dengan akhir pembelajaran, (2) wawancara terpimpin dengan melakukan wawancara kepada pendiri yayasan, dan juga kepala sekolahnya serta salah satu pendidiknya guna untuk mengetahui pelaksanaan pembelajaran yang berkaitan dengan perencanaan pembelajaran, pelaksanaan pembelajaran dan evaluasi pem- belajaran, (3) dokumentasi digunakan untuk mendukung informasi yang diperlukan seperti foto ruangan atau kelas yang digunakan untuk pembelajaran dan sarana atau prasarana yang digunakan dalam pembelajaran. Teknik sampling dilakukan dengan purposive dan snowball sampling dengan mencari informasi dari pendiri dilanjutkan kepada sekolah dan guru yang ada di kelas. Keabsahan hasil penelitian dilakukan dengan validitasi dan reabilitas. Metode analisis data dilakukan dengan cara: (a) pengumpulan daya, (b) reduksi data, (c) penyajian data, dan (d) verifikasi atau penarikan kesimpulan.

\section{HASIL DAN PEMBAHASAN}

Sekolah Dasar Quran Hanifah merupakan sekolah/madrasah tingkat dasar yang mengedepankan pada persiapan anak menuju akil baligh, sehingga menekankan pada aspek akhlaqul karimah. Sekolah Dasar Quran Hanifah memulai proses pembelajaran pada tahun ajaran 2015/2016 dengan kurikulum dinas dan ditambah kurikulum lokal khas pesantren yang fokus pada pembelajaran Al-Qur'an, serta dengan ekstrakurikuler yang merangsang bakat dan minat anak.

Tenaga edukatif yang berkualitas dan berpengalaman di bidangnya, Sekolah Dasar Quran Hanifah bertekad untuk mencetak generasi Qur'ani dan entrepreneurship yang handal dan berdayaguna. Serta memiliki wawasan ilmu pengetahuan dan teknologi sebagai wujud pengabdian kepada agama, bangsa dan negara di tengah krisis multi dimensi dewasa ini. Ditunjang oleh tenaga edukatif yang berkompeten di bidangnya antara lain alumni dari Universitas Negeri Semarang (UNNES), Universitas Islam Negeri (UIN) Walisongo, Universitas PGRI Semarang (UPGRIS), Universitas Wahid Hasyim (UNWAHAS) dan berbagai perguruan tinggi lainnya, serta alumni pondok pesantren, semakin memantapkan Sekolah Dasar Quran Hanifah untuk berperan membangun bangsa.

Berkaitan dengan visi Sekolah Dasar Quran Hanifah adalah Menjadi salah satu sekolah dasar Islam favorit di Indonesia, dan misinya adalah (1) Membina peserta didik, wali siswa, dan guru berakhlaqul karimah berdasarkan Al-Qur'an dan As-Sunnah (2) 
JPPM (Jurnal Pendidikan dan Pemberdayaan Masyarakat), 6 (1), 2019 - 5

Imam Shofwan, Ghanis Putra, Tristanti Tristanti

Menyelenggarakan pendidikan yang menyiapkan siswa ke arah kemandirian untuk berkreasi dan berinovasi. Selain itu berkiatan dengan output sekolahnya adalah: (1) terbiasa sholat lima waktu; (2) fasih membaca Al-Qur'an; (3) hafal 5 Juz Al-Qur'an, Asmaul Husna, 4o Hadits, dan do'a-do'a harian serta Sholawat; (4) rutin sholat dhuha dan sedekah; (5) berprestasi dalam bidang akademik, (6) rutin membaca; (7) berani menyampaikan ide atau gagasan; (8) menghasilkan karya sesuai bakat dan minat (passion); (9) memiliki dasar entrepreneurship.

Pembelajaran adalah proses interaksi peserta didik dengan pendidik dan sumber belajar pada suatu lingkungan belajar. Pembelajaran merupakan bantuan yang diberikan pendidik agar terjadi proses pemerolehan ilmu dan pengetahuan, serta pemberian sikap dan kepercayaan kepada peserta didik. Jadi dapat disimpulkan bahwa pembelajaran adalah proses untuk membantu peserta didik dapat belajar agar berjalan dengan baik.

Pembelajaran pendidikan nonformal dilakukan tidak kaku seperti pelaksanaan pendidikan formal yang dilakukan di sekolah-sekolah formal. Pembelajaran pendidikan nonformal tidak hanya sekedar atau mengutamakan pengetahuan, akan tetapi pembelajaran yang dilakukan lebih kearah pemberdayaan untuk menemukan dan mengembangkan potensi yang ada pada peserta didik.

Landasan dalam pembelajaran nonformal Sekolah Dasar Quran Hanifah sebenarnya adalah hampir sama dengan sekolah Alazhar. Sesuai dengan penelitian yang dilakukan oleh (Pramudyani \& Sugito, 2014) bahwa landasan dasar Al Qur'an dan hadist sebagai pedoman pembelajaran, anak-anak juga belajar untuk melakukan segala sesuatu di kehidupan sehari-hari agar dapat mengembangkan nilai etika Islam yang pada hakikatnya mampu meningkatkan kecerdasan emosi.

Berkenaan dengan kegiatan pembelajaran terdapat berbagai komponen yang saling berkaitan, yaitu diantaranya kurikulum, pendidik, peserta didik didik dan proses pembelajaran. Dalam pembelajaran pendidikan nonformal, pendidik berperan sebagai fasilitator yang dituntut harus mampu mengaplikasikan berbagai model pembelajaran yang memfasilitasi peserta didik supaya mau melakukan kegiatan belajar (Saripah \& Shantini, 2016).

\section{Perencanaan Pembelajaran Nonformal}

Perencanaan merupakan proses penetapan dan pemanfaatan sumber daya secara terpadu yang diharapkan dapat menunjang kegiatan dan upaya yang akan dilaksanakan secara efisien dan efektif dalam mencapai tujuan pembelajaran. Perencanaan pembelajaran adalah sesuatu yang harus dipersiapkan oleh pendidikan, agar dalam pembelajaran berjalan dengan efektif dan efisien. Senada dengan dengan pendapat (Hakim, 2009) berkiatan dengan pengertiaan perencanaan pembelajaran adalah suatu upaya untuk merancang dan mengembangkan setiap unsur pembelajaran, sehingga menjadi suatu kesatuan yang utuh, terkait, dan saling menentukan untuk mencapai tujuan pembelajaran.

Menurut Ketua Sekolah Dasar Quran Hanifah, peran pendidik dalam pembelajaran yang dapat membangkitkan aktivitas siswa setidak-tidaknya menjalankan tugas utama, berikut ini: (1) Merencanaan pembelajaran, yang terinci dalam empat sub kemampuan yaitu perumusan tujuan pembelajaran, penetapan materi pembelajaran, penetapan kegiatan belajar mengajar, penetapan metode dan media pembelajaran, penetapan alat evaluasi.

Perencanaan pembelajaran terdiri dari kalender akademik dan rencana kegiatan mingguan (RKM) yang dibagi wali murid di awal KBM sehingga orang tua juga bisa memantau perkembangan pembelajaran yang ada di sekolah. Menurut (Sanjaya, 2015) perencanaan pembelajaran merupakan proses penerjamahan kurikulum yang berlaku menjadi program-program pembelajaran yang selanjutnya dapat dijadikan pedoman pendidik dalam penyelanggaraan proses pembelajaran.

Adapun yang dijadikan dalam pedoman pendidik sebelum melakukan pembelajaran yang harus direncanakan adalah berkaitan dengan unsur-unsur pembelaaran diantaranya berkaitan dengan tujuan pembelajaran, materi pembelajaran, metode 


\title{
JPPM (Jurnal Pendidikan dan Pemberdayaan Masyarakat), 6 (1), 2019 - 6
}

\author{
Imam Shofwan, Ghanis Putra, Tristanti Tristanti
}

pembelajaran, teknik pembelajaran, media pembelajaran dan evalasi pembelajaran.

\section{Tujuan Pembelajaran}

Tujuan pembelajaran pada dasarnya merupakan harapan, yaitu apa yang diharapkan dari peserta didik sebagai hasil belajar. Batasan yang lebih jelas tentang tujuan pembelajaran, yaitu maksud yang dikomunikasikan melalui pernyataan dalam menggambarkan tentang perubahan yang diharapkan dari peserta didik.

Tujuan pembelajaran Sekolah Dasar Quran Hanifah adalah untuk menjadikan peserta didik berakhlaqul karimah dan mampu menghafal Alquran, untuk itu dalam proses pembelajaran yang dilakukan dengan melakukan pembelajaran dalam hal: (a) terbiasa sholat lima waktu; (b) fasih membaca Al-Qur'an, (c) hafal 5 Juz Al-Qur'an, Asmaul Husna, 40 hadits, dan doa-doa harian serta sholawat; (d) rutin sholat dhuha dan sedekah; (e) berprestasi dalam bidang akademik; (f) rutin membaca; (g) berani menyampaikan ide atau gagasan; (8) menghasilkan karya sesuai bakat dan minat (passion); (9) Memiliki dasar kewirausahaan atau entrepreneurship.

Materi Pembelajaran

Berkaitan dengan materi pembelajaran di Sekolah Dasar Quran Hanifah dibagi menjadi 3 hal, yaitu: mata pelajaran pokok, mata pelajaran muatan local, dan pengembangan diri.

Adapun mata pelajaran pokok terdiri dari: (a) Pendidikan Agama Islam (Alquran Hadist, Aqidah Akhlak, Fiqih, Sejarah Kebudayaan Islam); (b) Pendidikan Kewarganegaraan; (c) Bahasa Indonesia; (d) Matematika; (e) Ilmu Pengetahuan Alam; (f) Ilmu Pengetahuan Sosial; (g) Seni Budaya dan Keterampilan; (h) Pendidikan Jasmani, Olahraga dan Kesehatan.

Selain itu data mata pelajaran muatan lokal yaitu Tahfidz, Bahasa Arab dan Entrepreneur dan juga, berkaitan dengan pengembangan diri, dengan pengembangan potensi peserta didik yang disesuikan dengan minat kegiatan berkaitan dengan pengembangan diri antara lain: English Course, Bahasa Arab, Drumband, Rebana dan Pramuka.
Materi pembelajaran pada dasarnya merupakan isi dari kurikulum, yakni berupa mata pelajaran atau bidang studi dengan topik/sub topik dan rinciannya. Isi dari proses pembelajaran tercermin dalam materi pembelajaran yang dipelajari oleh siswa. (Djamarah \& Zain, 2010) menerangkan materi pembelajaran adalah substansi yang akan disampaikan dalam proses belajar mengajar. Tanpa materi pembelajaran proses belajar mengajar tidak akan berjalan.

\section{Metode Pembelajaran}

Metode pembelajaran merupakan cara melakukan atau menyajikan, menguraikan, dan memberi latihan isi pelajaran kepada siswa untuk mencapai tujuan tertentu. Metode pembelajaran yang ditetapkan guru memungkinkan siswa untuk belajar proses, bukan hanya belajar produk. Belajar produk pada umumnya hanya menekankan pada segi kognitif. Sedangkan belajar proses dapat memungkinkan tercapainya tujuan belajar baik segi kognitif, afektif, maupun psikomotor. Oleh karena itu, metode pembelajaran pembelajaran diarahkan untuk mencapai sasaran tersebut, yaitu lebih banyak menekankan pembelajaran melalui proses. Terdapat beberapa metode pembelajaran yang dapat digunakan untuk mengimplementasikan strategi pembelajaran, diantaranya: (a) ceramah; (b) demonstrasi; (c) diskusi; (d) simulasi; (e) laboratorium; (f) pengalaman lapangan; (g) brainstorming; (h) debat, (i) simposium, dan sebagainya.

Berkaitan dengan metode pembelajaran dibagi menjadi 2 (dua) yaitu metode pembelajaran umum dan metode pembelajaran tahfidz. Metode pembelajaran umum meliputi: (a) thematic teaching khusus kelas I s/d III; (b) pendidikan holistik berbasis akhlaqul karimah; (c) Brain Based Learning/BBL (pendidikan yang patut dan sesuai kerja otak); (d) dan berbagai macam model pembelajaran antara lain: (1) inquiry Learning (pembelajaran inquiri), (2) Project-Based Learning (pembelajaran berbasis proyek), (3) contextual learning (pembelajaran kontekstual), quantum teaching in action.

Metode pembelajaran Tahfidz di antaranya: (a) Metode Musyafahah: pada prinsipnya metode ini bisa dilakukan dengan 
tiga cara: (1) Guru membaca, santri mendengarkan dan sebaliknya, (2) Guru membaca dan santri hanya mendengarkan, (3) Santri membaca dan guru mendengarkan; (b) Metode Resitasi: Guru memberi tugas kepada santri untuk menghafal beberapa ayat atau halaman sampai hafal betul, kemudian santri membaca hafalannya di depan guru (setor hafalan); (c) Metode Takrir: Santri mengulang-ulang hafalan yang ia peroleh, kemudian membaca hafalannya di depan guru; (d) Metode Mudarrosah: semua santri menghafal secara bergantian dan berurutan, yang lain mendengarkan atau menyimaknya; (e) Metode tes yaitu digunakan untuk mengetahui ketepatan dan kelancaran hafalan santri dengan setor hafalan.

Teknik Pembelajaran

Teknik pembelajaran diawali dengan doa, asmaul husnah, kisah-kisah dan kadang diselingi humor agar suasana kelas menyenangkan kemudian kegiatan pembelajaran inti dan ditutup dengan motivasi dan doa.

\section{Media Pembelajaran}

Media Pembelajaran Al-Qur'an, kitab yanbua, buku bahan ajar sesuai kurikulum KTSP.

\section{Evaluasi Pembelajaan}

Mengenai evaluasi pembelajaran dilakukan tiga tahap, yaitu tahap awal pembelajaran, tahap proses pembelajaran dan pada akhir proses pembelajaran

\section{Proses Pelaksanaan Pembelajaran Nonformal}

Sebagai seorang pendidik kita semua memahami bahwa pembelajaran merupakan suatu yang kompleks, dimana tidak hanya transfer of knowledge atau menyampaikan pesan kepada peserta didik akan tetapi merupakan aktivitas profesional untuk menciptakan pembelajaran yang kondusif, inspiratif, menantang dan menyenangkan. Tentu saja mencapai kondisi tersebut bukanlah hal yang mudah, karena menuntut keterampilan pendidik dalam menata dan melaksanakan pembelajaran di dalam kelas ataupun di luar kelas.

Pelaksanaan pembelajaran yang termasuk di dalamnya adalah penilaian pencapaian tujuan pembelajaran. Proses pelaksanaan pembelajaran adalah berkaitan dengan interaksi yang dilakukan oleh pendidik dengan peserta didik dengan prosesnya mentransfer pengetahuan agar mempunyai wawasan atau pengetahuan yang luas. Selain itu mendidik berkaitan dengan kepribadian dan menumbuh kembangkan dalam kemampuan atau potensi yang dimiliki oleh peserta didik.

Pelaksanaan pembelajaran merupakan proses yang diatur sedemikian rupa menurut langkah-langkah tertentu agar pelaksanaan mencapai hasil yang diharapkan (Sukmadinata, 2012). Menurut (Djamarah \& Zain, 2010) pelaksanaan pembelajaran adalah suatu kegiatan yang bernilai edukatif, nilai edukatif mewarnai interaksi yang terjadi antara pendidik dan peserta didik. Pelaksanaan pembelajaran adalah proses yang diatur sedemikian rupa menurut langkah-langkah tertentu agar pelaksanaan mencapai hasil yang diharapkan (Sukmadinata, 2012).

Berkaitan dengan pelaksanaan pembelajaran yang dilakukan dimulai dari membuka pembelajaran, menyampaikan pembelajaran dan menutup pembelajaran yang berlangsungnya dalam proses interaksi peserta didik, dengan guru pada suatu lingkungan belajar.

Adapun dalam prosesnya dilakukan dengan komunikasi yang dapat dilakukan secara verbal (lisan), dan dapat pula secara nonverbal (gerakan, simbol).

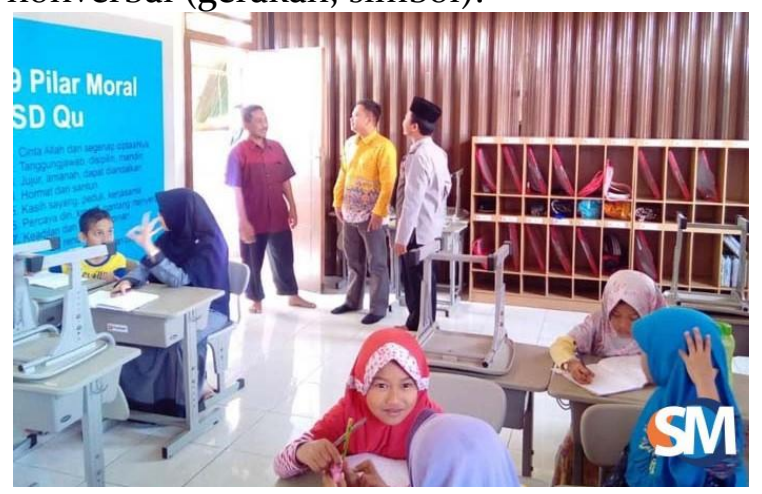

Gambar 1. Proses pembelajaran berlangsung

Kegiatan awal

Pembukaaan pembelajaran diawali dengan doa dan adab belajar atau peraturanperaturan kelas dilanjut dengan kisah-kisah untuk membentuk karakter peserta didik. 


\section{JPPM (Jurnal Pendidikan dan Pemberdayaan Masyarakat), 6 (1), 2019 - 8}

Imam Shofwan, Ghanis Putra, Tristanti Tristanti

Kegiatan Inti

Kegiatan inti sesuai dengan materi yang diberikan seperti pelajaran tahfidz, matematika dan lain sebagainya.

Kegiatan Penutup

Penutupan diakhiri dengan rutinitas akhir kegiatan belajar mengajar dengan menyiapkan berbagai peralatan yang harus dirapikan kembali, meja bersih, rapi dan terakhir pendidik bercerita tentang kisahkisah inspirasi dan doa pulang.

\section{Evaluasi Pembelajaran Nonformal}

Penilaian otentik merupakan proses evaluasi yang melibatkan berbagai bentuk penilaian kinerja mencerminkan belajar siswa, prestasi, motivasi, dan sikap pada kegiatan instruksional yang relevan (Fitria \& Suparno, 2016). Dalam bidang pendidikan evaluasi dibedakan atas evaluasi hasil belajar dan evaluasi program pendidikan. Evaluasi hasil belajar bertujuan mengukur ketercapaian tujuan yang dirumuskan. Evaluasi hasil belajar dilakukan dengan objek siswa, melalui pekerjaan rumah, ulangan harian, ujian nasional. Evaluasi program pendidikan dila kukan untuk mengevaluasi berbagai aspek pendidikan seperti kurikulum, tenaga pendidik, proses dan metode pembelajaran dan sebagainya. (Handoko \& Wuradji, 2015).

Fungsi utama evaluasi adalah menelaah suatu objek atau keadaan untuk mendapatkan informasi yang tapat sebagai dasar untuk pengambilan keputusan. Tujuan umum evaluasi pembelajaran adalah untuk menghimpun bahan-bahan keterangan yang akan dijadikan sebagai bukti menganai informasi perkembangan atau kemajuan yang telah dialami oleh peserta didik setelah mengikuti proses pembelajaran dalam jangka waktu yang telah ditentukan. Fungsi evaluasi pembelajaran sangat diperlukan dalam dunia pendidikan. Mengevaluasi pembelajaran dimana evaluasi ini merupakan salah satu komponen pengukur derajat keberhasilan pencapaian tujuan, dan keefektifan proses pembelajaran yang dilaksanakan.

Evaluasi pembelajaran adalah tahap akhir dalam proses pembelajaran dan untuk menentukan keberhasilan pembelajaran. Menurut (Arifin, 2014) pengertian evaluasi pembelajaran adalah suatu proses atau kegiatan yang sistematis, berkelanjutan dan menyeluruh dalam rangka pengendalian, penjaminan dan penetapan kualitas (nilai dan arti) pembelajaran terhadap berbagai komponen pembelajaran, berdasarkan pertimbangan dan kriteria tertentu, sebagai bentuk pertanggungjawaban pendidikan dalam melaksanakan pembelajaran.

\section{Evaluasi Awal Pembelajaran}

Setiap tahun ajaran baru dilakukan test awal baik kemampuan baca, hafalan dan psikologi guna sebagai bahan dasar penentuan proses kegiaan belajar mengajar kepada peserta didik.

Evaluasi Proses Pembelajaran

Ada tes kepada tiap peserta didik yang dilakukan untuk mengetahui hafalan pada awal kegiatan pembelajaran setiap harinya.

\section{Evaluasi Akhir Pembelajaran}

Ada tes tiap mingguan dengan mengisi anecdotal, bulanan dan semesteran dengan adanya tes atau ujian.

\section{Faktor Pendukung dan Penghambat dalam Pelaksanaan Pembelajaran Nonformal}

\section{Faktor Pendukung}

Faktor pendukung berkaitan dengan fasilitas sekolah dengan desain ramah lingkungan karena tanpa $\mathrm{AC}$ ruangan bisa dingin, sehingga pembelajaran lebih nyaman. Selain itu ada meja dan bangku modern sehingga bisa digunakan dengan berbagai macam posisi pembelajaran.

Selain itu didukung pendidik atau guru Tahfidzh bersyahadah 30 juz dari para gurunya. Selain itu berkaitan setiap 2 minggu sekali ada kegiatan parenting dengan mendatangkan orangtua untuk bekerjasama dalam mendidik karakter dan pengembangan potensi anak agar menjadi pribadi yang baik.

\section{Faktor Penghambat}

Berkaitan dengan lahan sekolah yang kurang luas, dan kualifikasi pendidik ada yang tidak sesuai karena ada yang belum lulus sarjana. 
JPPM (Jurnal Pendidikan dan Pemberdayaan Masyarakat), 6 (1), 2019 - 9

Imam Shofwan, Ghanis Putra, Tristanti Tristanti

\section{SIMPULAN}

Tujuan pembelajaran Sekolah Dasar Quran Hanifah adalah untuk menjadikan peserta didik berakhlaqul karimah dan mampu menghafal Alquran dengan metode pembelajaran dibagi menjadi 2 (dua) yaitu metode pembelajaran umum dan metode pembelajaran tahfidz. Perencanaan pembelajaran di Sekolah Dasar Quran Hanifah dimuat dalam kalender akademik dan rencana kegiatan mingguan (RKM) yang dibagi wali murid di awal KBM sehingga orang tua juga bisa memantau perkembangan pembelajaran yang ada di sekolah.

Proses pelaksanaan pembelajaran dibagi menjadi 3 (tiga) tahapan: (1) awal pembelajaran, diawali dengan doa dan adab belajar atau peraturan-peraturan kelas dilanjut dengan kisah-kisah untuk membentuk karakter peserta didik; (2) kegiatan inti, sesuai dengan materi yang diberikan seperti pelajaran tahfidz, matematika dan lain sebagainya; (3) kegiatan penutupan, diakhiri dengan rutinitas akhir kegiatan belajar mengajar dengan menyiapkan berbagai peralatan yang harus dirapikan kembali, meja bersih, rapi dan terakhir pendidik bercerita tentang kisah-kisah inspirasi dan doa pulang.

Evaluasi pembelajaran dibagi menjadi tiga 3 tahapan: (1) evalauasi di awal, dilakukan test awal baik kemampuan baca, hafalan dan psikologi guna sebagai bahan dasar penentuan proses kegiatan belajar mengajar kepada peserta didik; (2) evaluasi proses pembelajaran, tes kepada tiap peserta didik yang dilakukan untuk mengetahui hafalan pada awal kegiatan pembelajaran setiap harinya; (3) evaluasi akhir pembelajaran, dilakukan tes setiap mingguan dengan mengisi anecdotal, bulanan dan semesteran dengan adanya tes atau ujian.

Berkaitan dengan faktor pendukung dalam pelaksanaan pembelajaran di Sekolah Dasar Quran Hanifah adalah ruangan yang nyaman, pendidiknya penghafal Alquran dan adanya kegiatan parenting yang dilakukan setiap 2 (dua) minggu sekali. Selain itu berkaitan dengan faktor penghambatnya adalah lahan yang sempit dan juga pendidik secara kualifikasi belum sesuai karena sebagian belum lulus sarjana.
Berkaitan dengan saran adalah terkait degan faktor penghambatnya adalah lahan yang sempit, untuk itu disediakan lahan agar luas dan nyaman dan menyenangkan dalam proses pembelajaran di sekolah. Berkaitan dengan pendidik secara kualifikasi belum sesuai karena sebagian belum lulus sarjana, untuk itu ustadz/ustadzah yang belum sarjana/lulus untuk dipacu agar lulus tepat waktu. Selain itu mencari tenaga pendidik yang dengan prasyarat harus lulus sarjana.

\section{DAFTAR PUSTAKA}

Arifin, Z. (2014). Evaluasi pembelajaran: Prinsip, teknik, prosedur. Bandung: Rosdakarya.

Delors, J. (1998). Education for the twenty-first century: Issues and prospects. Unesco.

Departemen Pendidikan Nasional Republik Indonesia. (2006). Standar kompetensi PTK-PNF dan sistem penilaian. Jakarta: Direktorat Jenderal Peningkatan Mutu Pendidik dan Tenaga Kependidikan, Direktorat Pendidik dan Tenaga Kependidikan Pendidikan Nonformal, Departemen Pendidikan Nasional.

Djamarah, S. B., \& Zain, A. (2010). Strategi belajar mengajar. Jakarta: Rineka Cipta.

Ernawati, E., \& Mulyono, S. E. (2017). Manajemen pembelajaran program paket C di PKBM Bangkit Kota Semarang. Journal of Nonformal Education, $\quad 3(1), \quad 60-71$. https://doi.org/10.15294/jne.v3i1.8915

Fitria, S., \& Suparno, S. (2016). Evaluasi pembelajaran keterampilan membaca permulaan di TK Fastrack Funschool kelas A program nusantara Yogyakarta. JPPM (Jurnal Pendidikan Dan Pemberdayaan Masyarakat), 3(1), 85. https://doi.org/10.21831/jppm.v3i1.6481

Hakim, L. (2009). Perencanaan pembelajaran. Bandung: Wacana Prima.

Handoko, H., \& Wuradji, W. (2015). Evaluasi program pendidikan dan pengembangan anak usia dini (PPAUD) di Kabupaten Kulon Progo. JPPM (Jurnal Pendidikan Dan Pemberdayaan Masyarakat), 2(1), 2438. 
JPPM (Jurnal Pendidikan dan Pemberdayaan Masyarakat), 6 (1), 2019 - 10 Imam Shofwan, Ghanis Putra, Tristanti Tristanti

https://doi.org/10.21831/jppm.v2i1.4841

Hidayat, D. (2016). Strategi pembelajaran partisipatif dalam meningkatkan hasil program pendidikan nonformal di Kabupaten Karawang. Journal of Nonformal Education, 2(1), 13-20. https://doi.org/10.15294/jne.v2i1.5309

Lestari, D. P., \& Suminar, T. (2016). Pola pembelajaran program kecakapan hidup menjahit di BLK Kabupaten Pekalongan. Journal of Nonformal Education, 2(2), 120-127. https://doi.org/10.15294/jne.v2i2.7155

Nengsih, Y. K., Sari, A., \& Helmi, H. (2018). Pengelolaan pembelajaran program paket $C$ pada pusat kegiatan belajar masyarakat dan sanggar kegiatan belajar di Kota Palembang. JPPM (Jurnal Pendidikan Dan Pemberdayaan Masyarakat), 5(1), 51-60. https://doi.org/10.21831/jppm.v5i1.1693 6

Ningrum, E. (2016). Pengembangan sumber daya manusia bidang pendidikan. Jurnal Geografi Gea, 9(1). https://doi.org/10.17509/gea.v9i1.1681

Pramudyani, A. V. R., \& Sugito, S. (2014). Implementasi pembelajaran terpadu terhadap perkembangan anak usia dini di KB-TK Islam Al Azhar 31 Yogyakarta. JPPM (Jurnal Pendidikan Dan Pemberdayaan Masyarakat), 1(2), 160173.

https://doi.org/10.21831/jppm.vii2.2686

Presiden Republik Indonesia. Undang-
Undang Republik Indonesia nomor 20 tahun 2003 tentang sistem pendidikan nasional, Pub. L. No. 20, UndangUndang Republik Indonesia 26 (2003). Indonesia.

Sanjaya, W. (2015). Perencanaan dan desain sistem pembelajaran. Jakarta: Kencana Prenadamedia Group.

Saripah, I., \& Shantini, Y. (2016). Implementasi model pembelajaran mandiri program pendidikan kecakapan hidup perempuan. JPPM (Jurnal Pendidikan Dan Pemberdayaan Masyarakat), $\quad 3(2), \quad 176$. https://doi.org/10.21831/jppm.v3i2.11545

Shofwan, I., \& Kuntoro, S. A. (2014). Pengelolaan program pembelajaran pendidikan alternatif komunitas belajar Qaryah Thayyibah di Salatiga Jawa Tengah. JPPM (Jurnal Pendidikan Dan Pemberdayaan Masyarakat), 1(1), 50-62.

https://doi.org/10.21831/jppm.vii1.2356

Sukmadinata, N. S. (2012). Metode penelitian pendidikan. Bandung: PT Remaja Rosdakarya.

Suryono, Y., \& Tohani, E. (2016). Inovasi pendidikan nonformal. Yogyakarta: Graha Cendekia.

Vibriyanthy, R., \& Fauziah, P. Y. (2014). Implementasi pendidikan karakter di Homeschooling Kak Seto Yogyakarta. JPPM (Jurnal Pendidikan Dan Pemberdayaan Masyarakat), 1(1), 75-85. https://doi.org/10.21831/jppm.v1i1.2358 